\title{
A new technique for mounting and testing frame- supported homograft aortic valves
}

\author{
R. J . D O N N EL L , ${ }^{1}$ F. DEXTER, P. B. DEVER A L L \\ and D. A. WA TSON \\ Leeds Regional Cardio-Thoracic Surgical Centre, Killingbeck Hospital, Leeds, and \\ Leeds Regional Tissue Bank, Pinderfields Hospital, Wakefield
}

The mounting of homograft aortic valves on rigid frames often produces cusp distortion leading to mechanical dysfunction. This dysfunction can be demonstrated by a simple testing apparatus. A technique of valve mounting has been developed which consistently results in a competent valve with exact and correct cusp apposition. It is clear that the effect of different techniques of sterilization and preservation on valve function cannot be adequately assessed unless valves are mechanically correct at the time of insertion.

Homograft aortic valves have been used for aortic valve replacement since 1962 (Ross, 1962 ; BarrattBoyes, 1964) and large series have been reported (Davies, Missen, Blandford, Roberts, Lessof, and Ross, 1968 ; Malm, Bowman, Harris, and Kowalik, 1967; Karp and Kirklin, 1969; Barratt-Boyes and Roche, 1969; Barratt-Boyes et al., 1969). The main practical advantage of homograft valves is almost complete freedom from thrombosis and embolism.

Free homografts, however, have certain disadvantages:

(a) There is no fully satisfactory means of assessing the competence of the valve or the conformity of the valve cusps at the time of insertion. This mechanical incompetence accounts for the incidence of early diastolic murmurs (Malm et al., 1967 ; Karp and Kirklin, 1969; Barratt-Boyes et al., 1969; Duvoisin et al., 1968).

(b) Insertion, in general, takes approximately twice as long as that of a mechanical prosthesis. It is, therefore, less suitable in the poor-risk patient, the patient with severe coronary artery disease, and in multi-valve surgery (Karp and Kirklin, 1969).

(c) Free homografts cannot be used in the atrioventricular position.

(d) The severely dilated aortic root or the expectation of further dilatation after operation is generally accepted to be a contraindication to the

'Supported by a grant from the National Heart Research Fund use of a free homograft (Ross, 1966; Karp and Kirklin, 1969 ; Malm et al., 1967).

(e) The optimal method of valve sterilization and preservation is still not known.

Most of these disadvantages would be overcome if a homograft valve could be reliably mountec on a support frame.

Our experience with frame-supported valves suggests that a meticulous mounting technique is essential in order to achieve the precise alignmen of the valve cusps without which the valve is un likely to function in a satisfactory manner even in the short term. The importance of an exact. suturing technique on the fate of a graft is sup $\delta$ ported by Karp and Kirklin (1969), Barratt-Boyes et al. (1969), Davies et al. (1968), Duran, Whiteo head, and Gunning (1969), Carpentier et al. (1969) and Wright, Stacey, and Johnston (1968). Without correct mechanical function it is impossible to make a full assessment of other factors relevane to valve performance.

We have developed a technique for preparing frame-mounted grafts in which the cusps remain closed, competent, and in correct apposition to one another during the mounting process. A simple sterilizable testing apparatus, which had demon strated the inadequacy of previous mounting tech 0 niques, is now used both in the laboratory an $\Phi$ in the operating theatre to assess the prepared valve.

SELECTION OF VALVES

Homograft aortic valves are collected unsteril@ 
from donors below the age of 45 at routine necropsy within 48 hours of death. Only valves completely free from atheroma and calcification are accepted. If more than a small amount of fenestration of the valve cusp is present, the valve is rejected.

The valves are stored at $4^{\circ} \mathrm{C}$ in Hanks solution (Oxoid) containing penicillin, 100 units $/ \mathrm{ml}$, and

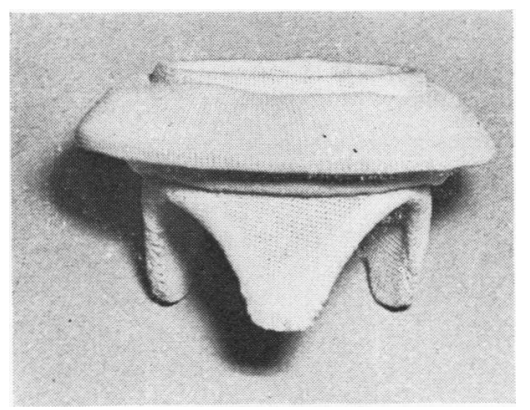

FIG. 1. Killingbeck-Lusterlite graft support ring for mitral valve replacement. streptomycin, $0.1 \mathrm{mg} / \mathrm{ml}$. Within five days the valves are mounted on to Killingbeck-Lusterlite ${ }^{1}$ graft support frames (Fig. 1) under non-sterile conditions.

\section{MOUNTING APPARATUS (Fig. 2)}

The mounting apparatus consists of a glass reservoir and column (A) connected by taps and tubing to a glass tube (B) with a lip on the protruding end. The apparatus is connected to a sphygmomanometer through a side arm and water-seal reservoir $(\mathbf{C})$.

\section{MOUNTING TECHNIQUE}

The coronary arteries are tied off and the three commissural attachments marked with a suture on the outside of the graft. About 1 in $(25.4 \mathrm{~mm})$ of ascending aorta is left above the commissures and this segment is slipped over the outside of the glass tube (B in Fig. 2) and is secured with a surrounding ligature (Fig. 3).

1Available from Lusterlite Products Ltd., 56 Devon Road, Leed LS2 9BA.

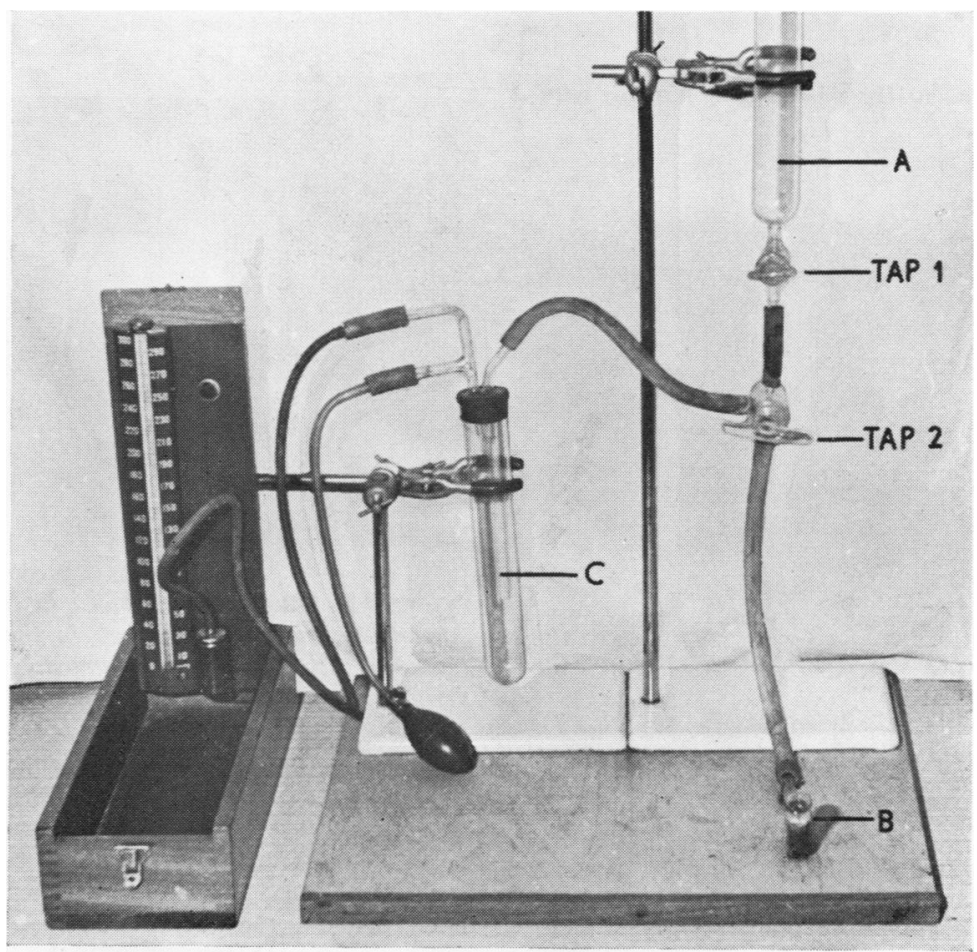

FIG. 2. Mounting apparatus : see text for details. 
Taps 1 and 2 , connecting the reservoir with the graft, are opened and the pressure of the column of water distends the valve and apposes the cusps (Fig. 4). Tap 1 is closed and the sphygmomanometer is used to exert a pressure of $70-80 \mathrm{mmHg}$ on the valve so that the cusps assume their functional position. A graft support ring is selected which fits snugly around the distended valve. The ring is positioned so that the ring legs overlap the previously marked commissural attachments. The base of the valve cusps should be within 2-3 mm of the lower edge of the support ring. It is important to position the cusps near this lower edge as the full length of the legs is required to accommodate the commissures.

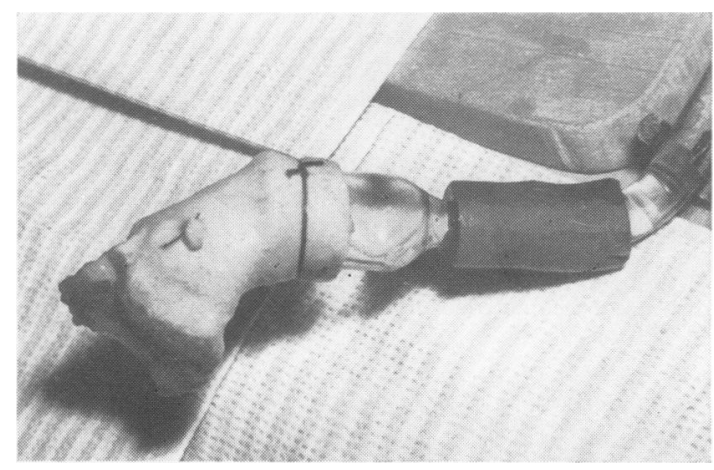

FIG. 3. Graft secured to the mounting apparatus with a surrounding ligature.

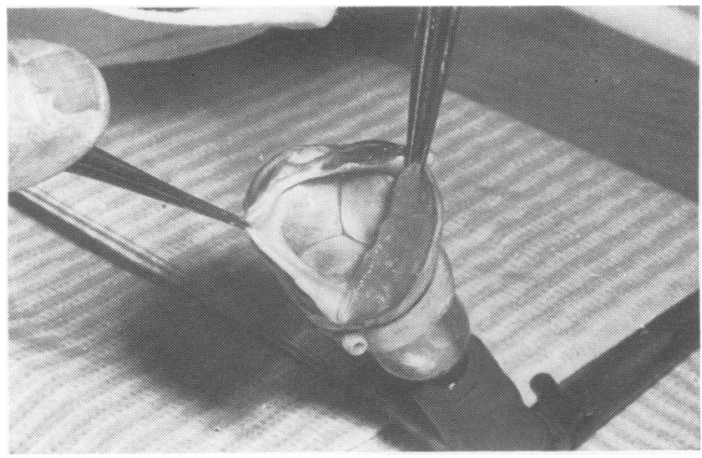

FIG. 4. Graft under pressure of $80 \mathrm{mmHg}$. The cusps are competent and perfectly apposed. Mounting takes place in this position.

The valve skirt is trimmed flush with the lower edge of the ring and six equidistant fixation sutures (3/0 polyester) are inserted between the graft and the ring. Since this is done with the cusps correctly apposed and competent, it is obvious if any suture causes cusp distortion. The fixation of the lower edge is now cont pleted with a running suture (Fig. 5).

Sutures are next placed, one at the top of each le and one at the midpoint of each sinus, suturing th Dacron of the ring to a partial thickness bite of aort wall. The graft can be rotated freely around the glass tube to facilitate exposure. Insertion of these sutures secures the upper graft margin.

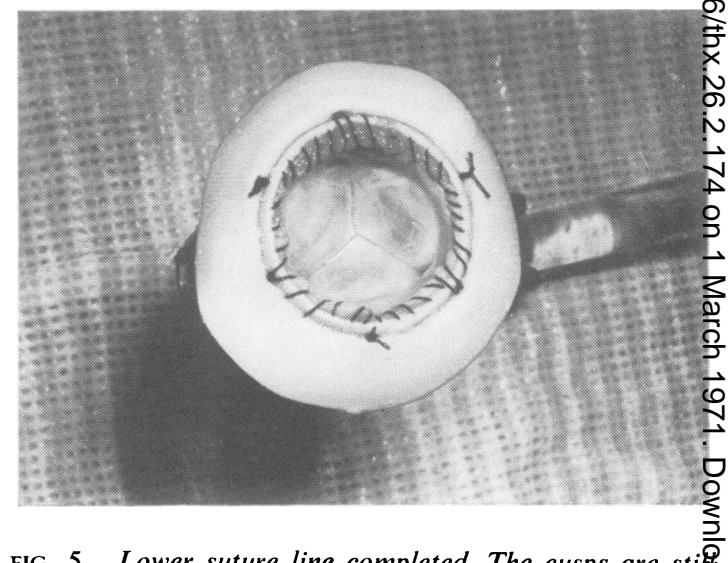

FIG. 5. Lower suture line completed. The cusps are sti under pressure and their relationship to one another has noकी been disturbed.

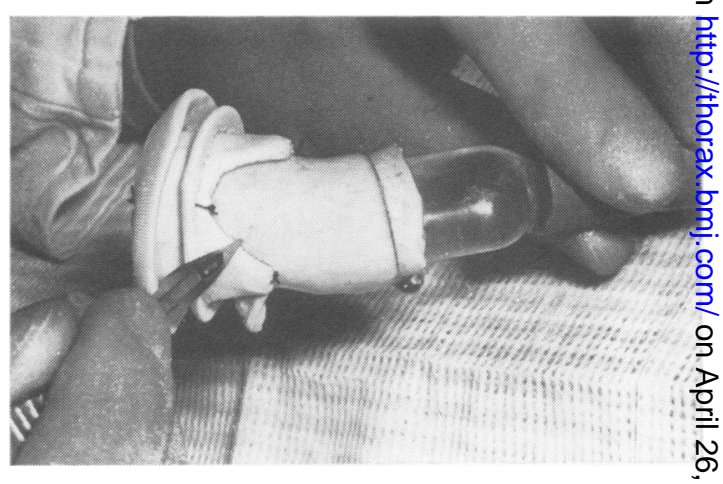

FIG. 6. Holding sutures placed in the upper margin. partial thickness cut is made in the aortic wall befores reducing the pressure and removing the graft from the mounting apparatus.

A partial thickness cut is now made with a knife $\mathrm{in}^{+}$ the aortic wall around the whole of the upper edgo of the support frame (Fig. 6). The valve is remove from the mounting apparatus and the excess aortig wall above the commissures and in the sinuses excised, using the partial thickness cut as a guide ang taking care not to cut out the temporary holding sutures just inserted in the upper margin. The valve 


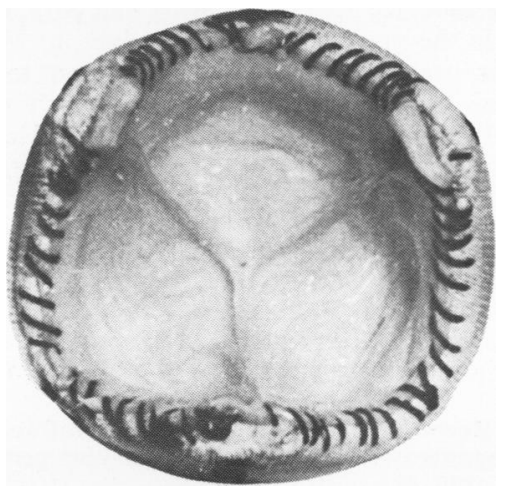

FIG. 7. Upper suture line completed. Valve cusps and commissures lie in correct apposition.

securely fixed to the frame with a mattress suture above each commissure and running sutures around the remainder of the upper edge (Fig. 7). These sutures are placed with care, avoiding distortion of the commissural attachments and ensuring that the upper edge of the graft approximates exactly to the upper edge of the support frame.

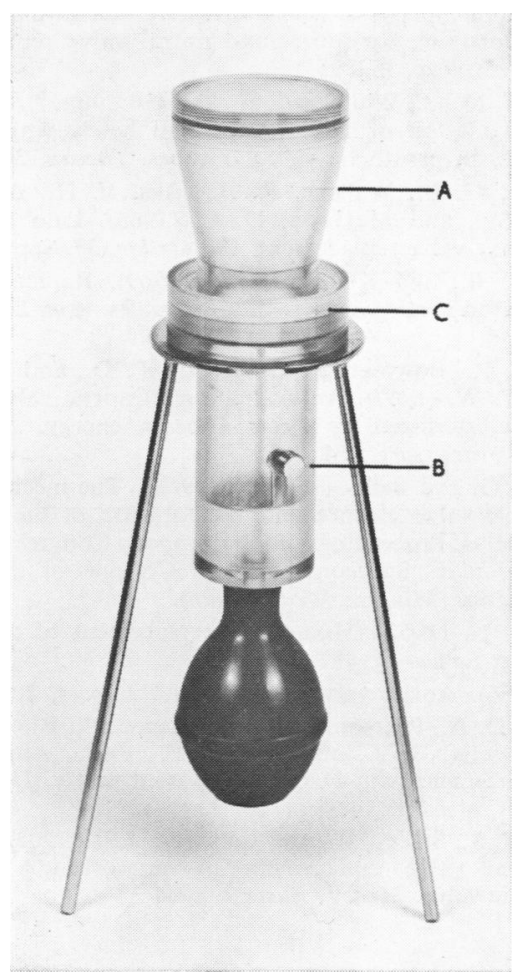

FIG. 8. Testing apparatus : see text for details.
Mounting is now complete and the valve is ready for examination in the testing apparatus.

\section{TESTING APPARATUS (Fig. 8)}

The apparatus is made of polycarbonate and consists of an upper and lower chamber (A and B) united by a housing $(C)$ in which the valve under test is seated. A rubber bulb is attached to the lower chamber and the upper chamber has a screw-in lid. The valve can be seated in the housing in the upright or inverted position. When the apparatus is primed with fluid, cusp movement and position are observed during opening and closing by manipulation of the rubber bulb. By appropriate manipulation of the apparatus, with the valve in the inverted position, it is possible to fill the upper chamber with fluid and yet have an air pocket below the valve in the lower chamber. Any incompetence of the valve is then demonstrated by compression of the rubber bulb. This raises the air pressure in the lower chamber and the presence and site of incompetence are directly observed from above as air bubbles escape into the upper fluid-filled chamber.

A single compression of the rubber bulb can produce a transient pressure of $80-140 \mathrm{mmHg}$ on the valve. A pressure gradient across the valve cannot be maintained because leakage of air and water occurs through the Dacron covering of the frame, resulting in rapid equalization of pressure in the two chambers.

\section{VALVE STERILIZATION}

The tested valve in $20 \mathrm{ml}$ Hanks solution is sealed in double polythene bags. The inner bag is sealed in the manner described by Cortes and Reed (1969) to prevent damage to the tissue. The valves are kept at $4^{\circ} \mathrm{C}$ before, during, and after sterilization. This is achieved with 2.5 megarads of gamma radiation from a spent fuel source. The dosage duration time depends on the age of the spent fuel and varies between one and three hours. At the time of operation, a valve of appropriate size is selected and tested again in the sterilized testing apparatus immediately before insertion.

\section{COMMENT}

It is not the purpose of this paper to discuss clinical experience with frame-mounted homografts. This has been reported elsewhere (Watson et al., 1968 ; Angell, Stinson, Iben, and Shumway, 1968 ; Donnelly, Rhea, and Watson, 1969). Nor 
is it our intention to discuss the relative merits of the different biological tissue valves or the various methods of sterilization and preservation. Our purpose is to emphasize the importance of obtaining optimal mechanical valve function before these other factors can be adequately assessed and to describe a method of achieving this.

Reid and Bellhouse (1968) have studied the function of the aortic valve and documented its very precise mechanical function. It is clear that either a free aortic homograft or a frame-mounted aortic homograft must be precisely sutured if it is to function in a mechanically correct fashion. In reviewing their experience with free aortic homografts, Karp and Kirklin (1969) say 'precision in seating the valve and positioning the commissural pillars is essential', and Barratt-Boyes et al. (1969) state 'For good long-term function, not only must the valve itself be initially perfect, but it must also be perfectly positioned'. These statements are equally true with regard to framemounted valves (Wright et al., 1968; Carpentier et al., 1969).

Visualization of the valve cusps under pressure in the testing apparatus disclosed significant faults in previous methods of mounting and testing. Although valve competence was usually achieved, it was apparent that the valve cusps did not lie correctly in relation to one another. The standardized technique of preparation now used has simplified mounting and regularly results in a competent valve with correct cusp apposition. This correct apposition does not necessarily imply symmetry of the valve cusps or commissures. Each valve has its own characteristics and the value of the method of mounting described is that these individual characteristics are preserved.

Immediate mechanical incompetence is thus eliminated. Long-term incompetence is more likely to reflect changes in valve structure related to techniques of sterilization and preservation or to be a consequence of long-term mechanical wear or some form of patient response to the homologous, non-viable tissue.

The testing apparatus can be used with all types of mounted biological valves. It can be used either on the laboratory bench or under sterile conditions in the operating theatre where it provides a final check on the mechanical integrity of the valve about to be inserted.
We are indebted to Mr. F. Swift and Mrs. C. Sharp for help in the preparation of the valves, to Mrs. J. R. Milne for preparing the manuscript, and to Mr. B. Langh for the photographs. We also wish to thank Mr. R. H. Baynard of Lusterlite Products Limited for help in the development of the testing apparatus.

\section{REFERENCES}

Angell, W. W., Stinson, E. B., Iben, A. B., and Shumway, N. E. (1968). Multiple valve replacement with the fresh aortic homograft. J. thorac. cardiovasc. Surg., 56, 323.

Barratt-Boyes, B. G. (1964). Homograft aortic valve replacement in aortic incompetence and stenosis. Thorax, 19, 131.

— and Roche, A. H. G. (1969). A review of aortic valve î homografts over a six and one-half year period. Ann. Surg., 170, 483.

Brandt, P. W. T., Smith, J. C., and Lowe, J. B. (1969). Aortic homograft valve replacement. Circulation, 40, 763.

Carpentier, A., Lemaigre, G., Robert, L., Carpentier, S., and Dubost, C. (1969). Biological factors affecting longterm results of valvular heterografts. $J$. thorac. cardiovasc. Surg., 58, 467.

Cortes, L. E., and Reed, C. E. (1969). A simple, safe method of storing homografts. Ann. thorac. surg., 7, 42.

Davies, H., Missen, G. A. K., Blandford, G., Roberts, C. I., Lessof, M. H., and Ross, D. N. (1968). Homograft replacement of the aortic valve. Amer.J. Cardiol., 22, 195.

Donnelly, R. J., Rhea, W. G., and Watson, D. A. (1969). Further experience with the Killingbeck-Lusterlite graft support ring for aortic and mitral valve replacement. Amer. Surgn, 35, 895.

Duran, C. M. G., Whitehead, R., and Gunning, A. J. (1969). Implantation of homologous and heterologous aortic valves in prosthetic vascular tubes. Thorax, 24, 142.

Duvoisin, G. E., Wallace, R. B., Ellis, F. H., Anderson, M. W., and McGoon, D. C. (1968). Late results of cardiac-valve replacement. Circulation, 37, Suppl. II, 75.

Karp, R. B., and Kirklin, J. W. (1969). Replacement of ? diseased aortic valves with homografts. Ann. Surg., 169, 921.

Malm, J. R., Bowman, F. O., Harris, P. D., and Kowalik, A. T. W. (1967). An evaluation of aortic valve homografts sterilized by electron beam energy. $J$. thorac. cardiovasc. surg., 54, 471.

Reid, K. G. and Bellhouse, B. J. (1968). The mechanism of $D$ aortic valve closure and the function of the sinus of Valsalva. Proceedings of the European Congress of Card- $\mathrm{N}$ iovascular Surgeons, Royal College of Surgeons, $\mathcal{N}$ London. (Minerva Med., Milan).

Ross, D. N. (1962). Homograft replacement of the aortic valve. Lancet, $2,487$.

- (1966). Aortic valve replacement. Lancet, 2, 461.

Watson, D. A., Pearson, K. W., Cawley, J. C., Rhea, W. G., Donnelly, R. J., and Dexter, F. (1968). Aortic valve replacement with Dacron-supported grafts. Thorax, 23, 621.

Wright, J. S., Stacey, R., and Johnston, J. B. (1968). Human T mitral valve replacement by reinforced heterograft aortic valve. Med. J. Aust., 2, 1084. 